Landslides (2020) 17:1

DOI 10.1007/s10346-019-01328-y

Received: 12 November 2019

Accepted: 15 November 2019

Published online: 10 December 2019

(c) Springer-Verlag GmbH Germany

part of Springer Nature 2019
Shamila Nair-Bedouelle

\section{Foreword by Shamila Nair-Bedouelle for the Journal of the International Consortium on Landslides}

Landslides continue to strike, worldwide, causing loss of life and suffering, disrupting societal functions and derailing economic gains. The development of urban areas and of human settlements in mountainous and coastal zones which are at risk from landslides, combined with the effects of climate change, pose a threat to people's lives and livelihoods. The poorest and most vulnerable people continue to be the primary victims of landslide disasters.

Scientific knowledge and technological know-how provide significant tools to cope with landslide risk. However, there is an enormous gap between the available level of science and technologies and the practical use of it in many countries, regions and communities. We must not only enhance the advances of landslide science and strengthen its applications but also ensure that communities have "free" access to relevant techniques, in the spirit of "leaving no one behind". Furthermore, the cultures and the perception of landslide risk management very much vary from one country to another; therefore interactions between the landslide science community and other actors in societies must be upscaled. We must raise awareness on this issue and encourage the commitment of all involved stakeholders in promoting resilience to landslide risks.

UNESCO, in collaboration with the International Consortium on Landslides (ICL), supported the experts and the governments to monitor and assess the risk of landslides. For example, UNESCO and the Research Centre for the Integral Disaster Risk Management organized in Chile a regional training in 2017 to develop a landslides inventory map. A similar regional was organized by UNESCO in Ecuador in 2016 for capacity building on analysis and modelling of landslides. UNESCO organizes an International Summer school on rockslides targeting students and young researchers in Central Asian (CA) countries The Summer schools provide the young participants with a good opportunity to learn about landslides from well-known experts in this area.

We are less than a year away from the Fifth World Landslide Forum (WLF 5), to be hosted by the city of Kyoto, Japan, from 2-6 November 2020. UNESCO commends ICL and other co-organizers for their on-going efforts in preparing this major event. The Forum is expected to represent a milestone in the history of ICL and, more generally, in the agenda of landslide scientists and practitioners.

One of the major outcomes of WLF 5 will be the Kyoto 2020 Commitment for global promotion of understanding and reducing landslide disaster risk (KLC2020). This Commitment is expected to strengthen and expand the activities of the Sendai Partnerships 2015-2025 for Global Promotion of Understanding and Reducing Landslide Disaster Risk. The adoption of KLC2O20 will raise global awareness on landslide risk and will mobilize wider partnerships that draw together stakeholders from all levels of society, across different regions, sectors and disciplines. The Commitment underlines the need for integrated approaches to reach resilience. Governments, academic and scientific communities, NGOs, international organizations and local communities will hopefully join the momentum created by KLC2020 in promoting safety measures facing landslide risk: the concerted efforts of all these stakeholders are essential to building a culture of landslide disaster resilience.

As per its mandate, UNESCO contributes to an integrated Sustainable Development Goals (SDG) of the 2030 Agenda, including SDG 11, which has a bearing on disaster risk reduction. In shaping its contribution to the SDGs, UNESCO commits to greater integration in its approach to support its Member States, between its different mandates and disciplines and with partners such as ICL. In this context, UNESCO's support to ICL is unwavering. The two Organizations have a long history of cooperation and partnership. This can be traced back to 2002 when ICL was established. Since that time, UNESCO has been associated with almost all of ICL activities. I am very glad that ICL and UNESCO are mutually benefiting from their collaboration. I would like to thank ICL experts for the technical advice in different UNESCO projects and undertakings.

UNESCO is committed to contribute to the success of WLF 5 and we are pleased to actively engage in the organization of the Forum. UNESCO also welcomes and supports the planned Kyoto 2020 commitment and we are happy to be among the first group of Partners to have signed on it at the ICL Conference, which was hosted by UNESCO at its Headquarters in Paris in September 2019.

UNESCO greets all ICL members and pays tribute to Professor Kyoji Sassa, Secretary General and founder of ICL. Professor Sassa's remarkable contribution, dedication and commitment to ICL is ensuring that all communities build their necessary resilience to manage landslides and its effects on its people.

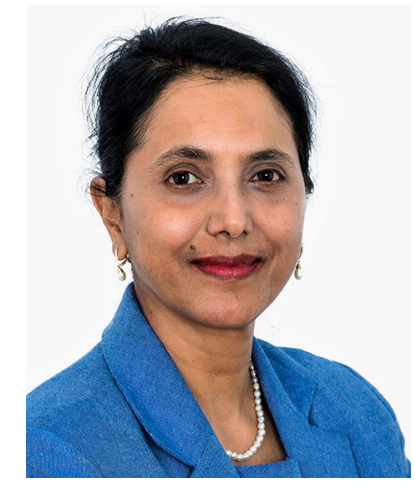

Shamila Nair-Bedouelle

Assistant Director-General for Natural Sciences UNESCO 